\title{
ENVIRONMENTAL ASSESMENT OF INTENSIVE EGG PRODUCTION: A SPANISH CASE STUDY
}

\author{
Rocío Abín, Amanda Laca, Adriana Laca*, Mario Díaz
}

Department of Chemical and Environmental Engineering. University of Oviedo. C/ Julián Clavería s/n. 33071 Oviedo. Spain

*Corresponding author: lacaadriana@uniovi.es

\begin{abstract}
Food production in intensive farming systems can be unsustainable in several ways. Although hen egg is consumed worldwide as a very valuable and cheap source of protein, there is an evident lack of studies concerning the environmental performance of egg production. The European Union produces approximately 7 million tonnes of useable eggs per annum and Spain is one of the largest egg producers.
\end{abstract}

In this work, Life Cycle Assessment (LCA) methodology was applied to analyse the environmental impacts of intensive egg production using as a model a Spanish farm with 55,000 laying hens, producing about 13 million eggs per year. High quality inventory data was obtained directly from this facility. The main factors involved in egg production were included (hen feed, water, electricity, transport, cleaning elements, packaging material, replacement of exhausted laying hens, wastes and gas emissions). Inventory data were analysed using the ReCiPe Midpoint (H) V1.12 / Europe Recipe H, the ReCiPe Endpoint (H) V1.12 / Europe Recipe H methods and the Greenhouse Gas Protocol V1.01 / C02 eq (kg) by means of the LCA software package SimaPro v7.

LCA results showed that, according to normalization results, natural land transformation was the most prominent category, followed by terrestrial ecotoxicity and 
freshwater ecotoxicity. The most important source of harmful environmental impacts in all the categories under assessment was the production of the hen feed and, to a lesser extent, the purchase of new laying hens to replace the old ones. On the contrary, water consumption and the employment of chemicals for cleaning barely influenced the impact. One aspect that was noteworthy was the beneficial effect on environmental impact produced by the sale of old laying hens for meat production, especially on the urban land occupation and metal depletion categories. Additionally, the carbon footprint of egg production was calculated and a value of $2.66 \mathrm{kgCO}_{2} \mathrm{eq}$ per dozen eggs was obtained. Environmental improvement actions should be directed mainly towards optimizing the hen feed formulation, not only from an economic perspective, but also considering the environmental aspects involved.

Keywords: LCA, laying hen farm, egg production, environmental impact, carbon footprint. negative environmental impacts such as greenhouse gas (GHG) emissions. In addition,

\section{INTRODUCTION}

The production of eggs worldwide has been increasing during recent decades. According to the FAO, in 2013 the global production of eggs had reached a volume of about 68 million tonnes (FAO, 2016). The European Union produces approximately 7 million tonnes of useable eggs per annum. Specifically, France and Spain are the largest egg producers (accounting for approximately a quarter of European production) (MAPAMA, 2017).

Food production requires large amounts of energy, which implies several since consumers in developed countries have started to demand high-quality food, 
51 produced under more environmentally friendly conditions (González-García et al., 52 2014), producers confront the contradictory demands of the need to increase food production while having to reduce the ecological impact of intensive production methods (Darnhofer et al., 2016). So, as occurs with other food industries, commercial egg production faces the challenge of producing high quality products in a way that meets consumer expectations, satisfies environmental regulations and maximizes profitability (Freeman et al., 2009). Moreover, egg producing farms are included in the Best Available Techniques (BAT) Reference Document for the Intensive Rearing of Poultry and Pigs contained in the Industrial Emissions Directive (IED, 2010/75/EU) issued by the European IPPC Bureau. Nevertheless, it was not until the 1980s that the environmental impact of intensive livestock farming was considered a problem. Awareness of the implications of farming activities such as the contamination of soil due to excess manure application and its impact on soil and water quality have increased over the years. Hence, the environmental impacts of agriculture and animal production have been increasingly acknowledged (Paolotti et al., 2016).

The poultry industry is one of the largest and most developed of the existing industries in the agriculture sector (Ghasempour and Ahmadi, 2016). In Spain in 2017 there were 1260 egg producing farms and the average number of hens per egg production facility was 67,700 . During the last few years, the tendency in Spain has been to increase the number of hens housed in cages, which now represent $93 \%$ of total laying hens (MAPAMA, 2017). Considering all EU countries, in contrast, this percentage is much lower $(40 \%)$, since free range production facilities are becoming more widespread due to public concern for animal welfare (Leenstra et al., 2014).

Life cycle assessment (LCA) is defined as a method for assessing environmental aspects and potential impacts associated with a product (Calderón et al., 2010; Calderón 
et al., 2017; Iglesias et al., 2012). It has been demonstrated to be a worthwhile tool for quantifying resource use and emissions in a wide range of primary sectors such as meat production (Cederberg, 2014; Velarde et al., 2015) and dairy farms (Hospido et al., 2003) and also in industrial sectors (Tecco et al., 2016; Vázquez-Rowe et al., 2012). In addition, the food system produces a large amount of GHG, specifically $33 \%$ of anthropogenic carbon emissions (Zhu et al., 2017). Furthermore, recently, the carbon footprint has been employed as a global measure of the production performance of different foodstuffs (Casolani et al., 2016).

There are papers targeting different aspects of the poultry meat chain (Cesari et al., 2017; Da Silva et al., 2014; González-García et al., 2014; Kalhor et al., 2016; Skunca et al., 2015; Wiedemann et al., 2017), but there is an evident lack of studies involving a life-cycle assessment approach for the environmental performance of egg production in egg producing farms. In fact, there are very few published studies regarding egg production (Cederberg et al., 2009; Dekker et al., 2011; Ghasempour and Ahmadi, 2016; Leinonen et al., 2012; Mollenhorst et al., 2006; Pelletier et al., 2013; Pelletier 2017). Thus, the aim of this study was to analyse the environmental performances of egg production in a laying hen farm in Asturias (a region in NW Spain), which has been selected as being representative of intensive European egg production. An LCA has been carried out in order to quantify its environmental impact, and to identify the activities with a major environmental impact, which would permit the establishment of a series of actions aimed at improvement of the situation. Additionally, the carbon footprint of egg production was also calculated.

\section{MATERIALS AND METHODS}




\subsection{LCA}

\subsubsection{Objectives and functional unit definition}

In this study, LCA methodology was used as a tool with the objective of determining the environmental impact of a Spanish-type laying hen farm. The functional unit was the annual egg production in 2015 (1,3344,000 eggs).

\subsubsection{System description and boundaries}

The laying hen farm involved in this research is situated in northern Spain (Asturias). The facility, which houses 55,000 laying hens, consists of two industrial units of $1540 \mathrm{~m}^{2}$ and $1430 \mathrm{~m}^{2}$, respectively. One of the units is also used as a storehouse for egg packing materials. In addition, an industrial unit of $500 \mathrm{~m}^{2}$ accommodates an egg-sorting room, an office and a toilet. The facilities are not connected to the municipal sewage system, so wastewater is stored and removed by an authorized company.

Laying hens employed in this farm are hybrids (Rhode Island Red/Light Sussex cross), medium sized (average weight $2.1 \mathrm{~kg}$ ), of brown colour with some soft white feathers. Following the ban on conventional cages for laying hens in the EU (Council Directive 1999/74/EC), hens are housed in suspended wire cages placed in four tiers along the length of each industrial unit (Big Dutchman EUROVENT-EV 1250a - EU $\left.60^{\circledR}\right)$. Sixteen-week-old hens are purchased and they are exploited for 75-80 weeks. After their productive life, exhausted hens are replaced by new laying hens and the old hens are sold for meat production. In 2015 all laying hens were removed and replaced with new ones. Hens are fed with commercial fodder for laying hens (see Table 1 for nutritional data) via automatic feed delivery systems and have continuous access to water supplied from nipple drinkers (6 stainless steel nipples per compartment). Eggs are collected daily by automatic belts, moved to the end of each industrial unit and then 
to a common egg-sorting room where they are packaged in recycled cardboard boxes and trays.

Polypropylene belts beneath the bottom wires collect the manure that is dried by means of an air duct (dry matter content of up to 60\%). The dried manure is removed twice a week and loaded directly onto a truck that carries it to a facility which commercialise it as fertilizer.

The system considered included the whole life cycle involved in the production of the eggs: transportation, consumption of energy and water, waste management and emissions.

\subsubsection{Inventory analysis}

Data were mainly collected through personal interviews with farmers. Additionally, some information was obtained from bibliographic sources. Inventory data have been organized into the subsystems shown in Figure 1 and they are summarized in Table 2. The following considerations were taken into account for the inventory analyses:

- With respect to packaging and fodder, only those elements that exceed $5 \%(\mathrm{w} / \mathrm{w})$ of the total were included, so the polyethylene around the pallets used to transport packaging materials was not considered $(<$ $0.05 \% \mathrm{w} / \mathrm{w})$

- Regarding cleaning materials, only bleach was included in the inventory, since it was the main cleaning agent employed (> 90\%).

- Drugs were not taken into consideration since they are only occasionally employed and, in addition, the amounts of these medicinal substances used in the farm were insignificant compared to the total incomes and outcomes. 
- Transport of raw materials (fodder, cleaning products, packaging material), new and old laying hens, wastes and eggs (from the farm to the retail store) was considered. Eggs are transported at room temperature in vans belonging to the farm. Data for these subsystems were included as tkm for external transport and as the diesel consumed by the company vans for internal transport (eggs). Note that the transport of the ingredients for the fodder has not been considered in this study.

- Wastewater was not generated by cleaning operations in the facilities since they used a dry cleaning technique employing compressed air. Therefore, it was assumed that $10 \%$ of consumed water was employed for the cleaning of transport vehicles and human uses (office toilet) and this water was considered as wastewater. It was supposed that the rest of the incoming water was consumed by the hens as drinking water.

- Emissions were calculated according to the stock sector PRTR emission factors (EPER-Spain): $0.0318 \mathrm{~kg} \mathrm{NH}_{3}-\mathrm{N}, 0.007642 \mathrm{~kg} \mathrm{~N}_{2} \mathrm{O}-\mathrm{N}$ and $0.08730 \mathrm{~kg} \mathrm{CH}_{4}$, given in all cases per hen and year (MAPAMA, 2017).

- Exhausted laying hens were sold for slaughtering and the meat is sold for human consumption. Hence, poultry meat is included in the system as an avoided product. The live weight of slaughtered hens was calculated supposing that each hen weighed $2.1 \mathrm{~kg}$ and that $96 \%$ of replaced hens were sold for slaughter. The remaining $4 \%$ were the hens that die and were managed as waste.

\subsubsection{Impact assessment}

Impact assessment was performed with the LCA software package SimaPro v7, using the ReCiPe Midpoint (H) V1.12 / Europe Recipe H method. This method includes 
17518 impact category indicators (climate change, ozone depletion, terrestrial acidification, 176 freshwater eutrophication, marine eutrophication, human toxicity, photochemical 177 oxidant formation, particulate matter formation, terrestrial ecotoxicity, freshwater ecotoxicity, marine ecotoxicity, ionising radiation, agricultural land occupation, urban land occupation, natural land transformation, water depletion, metal depletion and fossil 180 depletion) to reach wide impact category coverage and follows the latest recommendations of the LCA community (Heinonen et al., 2016). The ReCiPe Endpoint (H) V1.12 / Europe Recipe H method has also been employed with the aim of classifying the damage in only three categories: human health, ecosystems and resources. The ReCiPe method takes its origins from CML and Ecoindicator (Baldini et al., 2017) and it has been applied recently in different LCA studies focused on agrofood industries (Freón et al., 2014; Vázquez-Rowe et al., 2014; Arzoumanidis et al., 2017; Baldini et al., 2017; Khatri and Jain, 2017; Noya et al., 2017). The advantages of this method include (i) the broadest set of midpoint impact categories and (ii) the use of impact mechanisms that have global scope (Santos et al., 2017). soybean, palm oil) and LCA Food (sodium bicarbonate) databases. Data for new laying hens, exhausted laying hens for slaughtering, cleaning elements and water subsystems were obtained from the Agri-footprint database. Data for packaging material, electricity, wastes and emissions to air subsystems were taken from the EcoInvent database. Transport subsystem data were obtained from Agri-footprint (transport by track) and EcoInvent (diesel). Whenever it was possible "Alloc Def", which follows the attributional approach in which burdens are attributed proportionally to specific processes, was used. Additionally, regions and time span were selected considering the available information regarding the system studied. 


\subsection{Carbon Footprint}

202

The carbon footprint was obtained by employing the Greenhouse Gas Protocol

203

V1.01 / C02 eq (kg), again by means of the LCA software package SimaPro v7. This

204

205

206

207

208

209

210

211

212

213

214

215

216

217

218

219 method includes scopes 1 (all direct GHG emissions), 2 (indirect GHG emissions from consumption of purchased electricity, heat or steam) and also 3 (other indirect emissions, such as transport-related activities, waste disposal, etc.). In addition, it is the same method of analysis employed by the Spanish Ministry of Agriculture and Fishing, Food and Environment (MAPAMA, 2017).

\subsection{Alternative scenarios}

Two alternative scenarios to the real analysis (scenario 1) have been considered. As hen feeding turned out to be the most impacting subsystem, in scenario 2, pea was substituted for soybean, whereas, in scenario 3, the analysis examined the replacement of palm oil with cottonseed oil. The criteria followed for the substitution of ingredients have involved using the same mass of products for both scenarios.

\section{RESULTS AND DISCUSSION}

\subsection{Impact assessment}

Characterization results obtained with the ReCiPe Midpoint method revealed hen feed to be the subsystem with the highest environmental loads in almost all categories considered (Figure 2). Specifically, feed was responsible of more than 55\% of impact in all categories evaluated, excepting metal depletion (the contribution of feed here was $11 \%$ ) and urban land occupation (feed did not contribute to this category). 
225 Animal feed was responsible for more than $90 \%$ of impact in terrestrial ecotoxicity and natural land transformation categories. Additionally, it must be mentioned that the feed conversion ratio of the farm under study was $2.8 \mathrm{~kg}_{\text {feed }} / \mathrm{kg}_{\text {egg }}$, a value slightly higher than those found by Dekker et al. (2011) in loose housing systems (2.3-2.6) and in battery cage systems (2.0). It should be taken into account that the non-enriched battery cage systems studied in the previous investigation have been prohibited since 1 January 2012 by the Council Directive 1999/74/EC due to animal welfare concerns. On the contrary, the farm studied here fulfils the minimum requirement of $750 \mathrm{~cm}^{2}$ of cage area per hen fixed by European regulations, so a direct comparison cannot be established. The breeding of new hens that were purchased in 2015 was also an activity with emissions contributed $9 \%$ to terrestrial acidification, $7 \%$ to particulate matter formation and $5 \%$ to climate change, whereas electricity consumption was responsible for $12 \%$ 
be kept in mind that the use of radioactive material within nuclear reactors to generate electricity generates ionising radiation and in Spain nuclear energy is one of the main sources of electricity (MINETAD, 2017).

Finally, it is worth noting that some subsystems made a beneficial contribution in some categories. Specifically, the sale of exhausted laying hens for slaughter and also waste management had favourable effects on almost all categories, mainly on urban land occupation and metal depletion. Indeed, in these categories the global impact was seen to be advantageous to the environment. This can easily be explained, since the use of discarded laying hens for meat avoids the need to breed chickens raised with this specific aim, and it is well known that, among all animal products, the largest environmental impacts are usually associated with meat production (Xu and Lan, 2016). Farm processes were identified as the main contributors to the environmental impacts derived from chicken meat production. Specifically, along the production chain, broiler fattening is the phase that has most impact. On the contrary, hatchery, slaughterhouse and packaging have a low impact (Cesari et al., 2017; González-García et al., 2014). In addition, the reason for the beneficial effect of the waste subsystem observed in this work was mainly due to the recycling of waste cardboard, which avoided the consumption of virgin materials.

The normalization phase allows the comparison of all environmental impacts using the same scale. According to these outcomes, natural land transformation was the most prominent category, although terrestrial ecotoxicity was also of importance. The rest of the studied categories were less affected in comparison with those mentioned above.

As previously commented, the main contributor to natural land transformation was hen feeding, the soybean used as an ingredient in the fodder being responsible for 
$69 \%$ of the contribution of hen feeding to this category, whereas palm oil contributed $22 \%$. Again, hen feeding was the main subsystem with a harmful impact on terrestrial and freshwater ecotoxicity categories. However, in these cases, palm oil employed as an ingredient in the fodder originated approximately $60 \%$ of the impact, followed by soybean (around 30\%).

In Europe, soy and palm crops are partly or wholly produced overseas. Soy is imported mainly from Brazil and Argentina, where forest areas are being converted into agricultural land. In addition, the production of palm oil also implies land-use changes. Leinonen et al. (2012) reported that the use of soy and palm for feeding laying hens contributes notably to the global warming category, as a result of greenhouse gases being released by changes in land use.

It is clear that soybean cultivation is linked to serious environmental problems. In Brazil, soybean production has expanded rapidly in recent decades, whilst in Malaysia oil palm plantations are also expanding, sometimes with the sacrifice of invaluable rain forest (Mattsson et al., 2000). In addition, palm oil production is deeply related with forest transformation and land availability (Uusitalo et al., 2014). Hence, in many regions the production of these crops is a major cause of land use, but in addition, the use of glyphosate in palm oil production in Thailand notably contributes to freshwater ecotoxicity (Saswattecha et al., 2015).

The ReCiPe endpoint method allows all the impacts to be grouped into only three categories: human health, ecosystems and resources. As is shown in Figure 3, the ecosystems category was the most affected in the long-term. Again, in this category food was responsible for $81 \%$ of impact, whereas $9 \%$ was originated by acquisition of new laying hens. With respect to human health, these subsystems were responsible for 
$79 \%$ and $13 \%$ of impact, respectively. Resources were again affected by food (71\%) and the purchase of young chicks (14\%), but also by packaging materials (11\%).

These results are in agreement with those reported regarding the environmental impacts related to egg production in Iran (Ghasempour and Ahmadi, 2016) and also in Canada (Pelletier, 2017). In both cases, the composition and amount of feed consumed in egg producing facilities were found to be the largest contributors to harmful impacts.

\subsection{Carbon footprint}

Results obtained from the Green House Gas Protocol are shown in Figure 4. In the carbon footprint of the egg producing farm analysed here, scope 1 included the direct emissions that correspond to $\mathrm{N}_{2} \mathrm{O}$ and $\mathrm{CH}_{4}$ originated by hen housing and manure storage and also the emission derived from the diesel employed in product commercialization, since commercialization is carried out by the farm. Scope 2 also included emissions derived from electricity use. Considering scopes $1+2$, the farm had a carbon footprint of $342 \mathrm{t} \mathrm{CO}_{2}$ eq during 2015, i.e., $308 \mathrm{~g} \mathrm{CO}_{2}$ eq per dozen eggs. The major factor responsible for this value was direct emissions of $\mathrm{N}_{2} \mathrm{O}$ and $\mathrm{CH}_{4}$, which contributed approximately to the same degree. Scope 3 considers extraction and production of materials, management and treatment of generated wastes by the management company and transport activity carried out by personnel external to the farm itself. Considering only fossil and biogenic carbon, according to the ISO 14067 standard, when scope 3 is included a value of $2960 \mathrm{t} \mathrm{CO}_{2}$ eq was achieved for the year 2015. As was expected, hen feeding was again the main contributor to greenhouse gas emission (73\%), as was also found by other authors (Cederberg et al., 2009; Ghasempour and Ahmadi, 2016; Pelletier et al., 2013; Xu and Lan, 2016). 

(approximately $3.4 \mathrm{kgCO}_{2}$ eq per $\mathrm{kg}$ of eggs). This is a value within the range reported by Nijdam et al. (2012) (1.7-5.5 $\mathrm{kg} \mathrm{CO} 2$ eq for $1 \mathrm{~kg}$ of eggs) for the egg industry in (2016) for egg production systems in Netherlands (3.9-4.6 $\mathrm{kg} \mathrm{CO}_{2}$ eq for $1 \mathrm{~kg}$ of eggs), Pelletier et al. (2013) for packaged shell eggs in Iowa (4.2-6.0 $\mathrm{kg} \mathrm{CO}_{2}$ eq for $1 \mathrm{~kg}$ of eggs) and the value reported by Ghasempour and Ahmadi (2016) for egg production in Iran (4.07 $\mathrm{kg} \mathrm{CO} 2$ eq for $1 \mathrm{~kg}$ of eggs). The lowest published value for the carbon footprint for eggs at the farm-gate, corresponding to $1.4 \mathrm{~kg} \mathrm{CO}_{2}$ eq per $\mathrm{kg} \mathrm{egg}$, was described by Cederberg et al. (2009) for Swedish production systems.

These values help to confirm that eggs, together with milk (1-2 $\left.\mathrm{kg} \mathrm{CO}_{2} \mathrm{eq} \mathrm{kg}^{-1}\right)$ and chicken meat (2-6 $\mathrm{kg} \mathrm{CO}_{2} \mathrm{eq} \mathrm{kg}^{-1}$ ), turn out to be the animal products that cause least greenhouse emissions, especially if they are compared with foodstuffs such as beef meat (9-129 $\mathrm{kg} \mathrm{CO}_{2}$ eq kg-1), pork meat (4-11 $\mathrm{kg} \mathrm{CO}_{2}$ eq kg$\left.{ }^{-1}\right)$, lamb meat (10-150 kg $\mathrm{CO}_{2}$ eq $\mathrm{kg}^{-1}$ ), cheese $\left(6-22 \mathrm{~kg} \mathrm{CO}_{2}\right.$ eq kg ${ }^{-1}$ ) or shellfish (1-86 $\mathrm{kg} \mathrm{CO}_{2}$ eq kg $\mathrm{kg}^{-1}$ (Del Prado et al., 2013; Ghasempour and Ahmadi, 2016; Nijdam et al., 2012).

\subsection{Improvement actions}

As mentioned above, the activity responsible for most environmental impacts derived from intensive egg production in Spain was found to be the production of the hen feed, which is in accordance with results reported for egg production in the

344 Netherlands, the United Kingdom, Iran and Canada (Dekker et al., 2011; Leinonen et al., 2012; Ghasempour and Ahmadi, 2016; Pelletier, 2017). Similar conclusions were reached for broiler chicken production (González-García et al., 2014; Da Silva et al., 2014). 
Since soybean and palm oil employed as ingredients in the fodder used in the farm are mainly responsible for the impacts caused by hen feeding, the first environmental improvement that should be tried is the total or partial replacement of these ingredients in the fodder formulations. For instance, pea or bean can be employed instead of soybean, since both these crops have been tested successfully as ingredients in laying hen feed formulation (Koivunen et al., 2014; Koivunen et al., 2015). In the same way, palm oil could be substituted with other crop oils such as cotton, corn, flax, canola, olive or sunflower oils, which are often employed as components of fodders for laying hens (Balevi and Coskun, 2000; Ceylan et al., 2011, Yuan et al., 2014). As an example, two alternative scenarios (2 and 3) have been considered. In scenario 2, soybean was replaced with pea and, in scenario 3, the analysis was carried out substituting cottonseed oil for palm oil. It has been reported that the inclusion of pea in the feed formulation of the laying hens had no effects on production performance or egg quality (Kouvunen et al., 2015), and furthermore, egg yield, egg weight and shell quality was not affected by cotton oil in the feed formulation (Balevi and Coskun, 2000). Additionally, when selecting the alternative ingredients, their market prices were checked and found to be similar to those of the original ingredients. Besides, Spain is the second largest European producer of cotton and also peas, exporting to other countries (European Commission - Agricultural and Rural Development, 2017; EUROSTAT, 2017). One third of the Spanish land surface is cultivable; therefore, it is reasonable to expect that these alternative ingredients can be produced in situ with lower impacts.

According to normalization results, natural land transformation was the most important category, followed by terrestrial ecotoxicity and freshwater ecotoxicity. The pea option (scenario 2) reduced the impact of food on natural land transformation, 
373 freshwater ecotoxicity and terrestrial ecotoxicity by $69 \%, 28 \%$ and $30 \%$, respectively.

374 The cottonseed oil alternative (scenario 3) also reduced the impact of food on these 375 three categories, by 22\%, 32\% and 54\%, respectively (Figure 5). these variants in fodder formulation would be noticeable too, especially in scenario 3 (Figure 6). In fact, the use of cottonseed oil instead of palm oil reduced the impact in the carbon footprint by $22 \%$, giving a carbon footprint of $2.3 \mathrm{~kg} \mathrm{CO}_{2}$ eq per $\mathrm{kg}$ of eggs. These attempts to improve the environmental performance of farms through changes in the hen feed formulation were addressed from an environmental point of view. However, economical and nutritional aspects should be taken into account before implementing these modifications in hen fodder formulations. Concerning this matter, De Boer et al. (2014) investigated the replacement of American soybean meal for fattening pigs by other European protein sources. However, only a reduction of $2.5 \%$ in the carbon footprint could be achieved without increasing the efficiency of the ingredients production in Europe.

Besides, as previously mentioned, the feed conversion ratio is key with respect to the environmental impact of hen feeding. This parameter depends on different factors, such as the kind of housing system utilised. Dekker et al. (2011) reported that feed conversion is higher in loose housing compared with battery cage systems. Therefore, the design of farm facilities is also an important aspect to be borne in mind when attempting to decrease the impact of egg production (without breaching European regulations for animal welfare). Other factors that can contribute to decreasing the feed conversion ratio are changes in feed composition and the genetic selection of the laying hens (Dekker et al. 2011). 
Another aspect to be considered is the purchase of new chicks for replacement of exhausted laying hens, since it was another cause of high environmental impacts related to egg production. Again, the reformulation of the fodder consumed, in this case by the hens used to breed the new chicks, should be considered. Another possibility might be optimizing the productive life of laying hens from an environmental point of view. Nevertheless, extending the laying cycle is a complex issue, since not only economic aspects, but also the flocks' welfare should be taken into account. Additionally, different factors, including genetics, nutrition and the design of housing systems, should be considered to ensure that adverse effects are avoided (Bain et al., 2016).

\section{CONCLUSIONS}

A Spanish egg producing farm was taken as a model of intensive egg production in Europe and a study of the yearly environmental performance of the facility was carried out by LCA and carbon footprint calculation. The global warming potential resulting from the production of $1 \mathrm{~kg}$ of shell eggs was $3.5 \mathrm{kgCO}_{2}$ eq per $\mathrm{kg}$ of eggs, a value in the same order as those reported in other studies. Additionally, natural land transformation, and to a lesser extent, terrestrial ecotoxicity were the most notably affected categories, according to the normalization results. The most important source of environmental impacts in all the categories under assessment was hen feeding (specifically soybean and palm oil cultivation), but also the breeding of young chicks to replace exhausted laying hens. Thus, alternative feed formulations would be an important parameter to take into account in order to lessen the environmental impact. This question should be given serious consideration by the fodder industry and also by the governments that could legislate to limit the amounts of the most harmful 
422 components in fodder formulation with respect to environmental impact. An 423 optimisation of the production life of laying hens and actions to decrease the feed 424 conversion ratio could also reduce the environmental impact associated with egg 425 production. These changes should consider not only an environmental perspective, but 426 also productivity and economic aspects.

ACKNOWLEDGEMENTS

This study was carried out thanks to funding from the Economy and Employment Office of Principality of Asturias (Spain) through project GRUPIN14-140. "Asturiana de Avicultura, S.L." egg producing farm (San Cucao, Llanera 33425 Asturias) and especially, José Ramón García, is gratefully acknowledged for his kind collaboration in supplying the data employed in this research.

\section{REFERENCES} there a simplified LCA tool suitable for the agri-food industry? An assessment of selected tools. J. Clean. Prod. 149, 406-425.

Bain, M.M., Nys, Y., Dunn, I.C., 2016. Increasing persistency in lay and stabilising egg quality in longer laying cycles. What are the challenges? Br. Poult. Sci. 57, 330-338.

Baldini, C., Gardoni, D., Guarino, M., 2017. A critical review of the recent 444 evolution of Life Cycle Assessment applied to milk production. J. Clean. Prod. 140, 445 421-435. 
fatty acid composition of eggs in layers. Rev. Med. Vet. 151, 847-854.

Calderón, L.A., Iglesias, L., Laca, A., Herrero, M., Díaz, M., 2017.

Environmental impact of a traditional cooked dish at four different manufacturing scales: from ready meal industry and catering company to traditional restaurant and homemade. Int. J. Life Cycle Assess. (in press).

Casolani, N., Pattara, C., Liberatore, L., 2016. Water and Carbon footprint perspective in Italian durum wheat production. Land Use Policy 58, 394-402.

Cederberg, C., Sonesson, U., Henriksson, M., Sund, V., Davis, J., 2009.

Greenhouse gas emissions from Swedish production of meat, milk and eggs 1990 and 2005. SIK Report No 793.

Cederberg, C., 2014. Environmental impact of meat production. Primary Production/Meat and the Environment. Encyclopedia of Meat Sciences (Second Edition). Reference Module in Food Science, 502-507.

Cesari, V., Zucali, M., Sandrucci, A., Tamburini, A., Bava, L., Toschi, I., 2017. Environmental impact assessment of an Italian vertically integrated broiler system through a Life Cycle approach. J. Clean. Prod. 143, 904-911.

Ceylan, N., Ciftci, I., Mizrak, C., Kahraman, Z., Efil, H., 2011. Influence of different dietary oil sources on performance and fatty acid profile of egg yolk in laying hens. J. Animal Feed Sci. 20, 71-83. 
470 Environmental impacts of French and Brazilian broiler chicken production scenarios: 471 An LCA approach. J. Environ. Manage. 133, 222-231. family farms: Towards a relational approach. J. Rural Stud. 44, 111-122. of soybean meal in compound feed by European protein sources. Effects on carbon footprint. Bron Lelystad: Wageningen UR Livestock Research (Livestock research report 819).

Dekker, S.E.M., de Boer, I.J.M., Vermeij, I., Aarnink, A.J.A., Groot Koerkamp, P.W.G., 2011. Ecological and economic evaluation of Dutch egg production systems. Livest. Sci. 139, 109-121. interactions between $\mathrm{C}$ and $\mathrm{N}$ farm balances and $\mathrm{GHG}$ emissions from confinement dairy farms in northern Spain. Sci. Total Environ. 465, 156-165. https://ec.europa.eu/agriculture/ (accessed 24 November 2017). EUROSTAT, 2017. http://ec.europa.eu/eurostat/ (accessed 24 November 2017). FAO (Food and Agriculture Organization of the United Nations), 2016. http://www.fao.org/ (accessed 9 May 2017). methods for disposal of spent laying hens: Evaluation of the efficacy of grinding, mechanical deboning, and of keratinase in the rendering process. Bioresour. Technol. $100,4515-4520$. 

assessment of the Peruvian industrial anchoveta fleet: boundary setting in life cycle

495

496

497

498

499

500

501

502

503

504

505

506

507

508

509

510

511

512

513

514

515

516 inventory analyses of complex and plural means of production. Int. J. Life Cycle Assess. 19, 1068-1086.

Ghasempour, A., Ahmadi, E., 2016. Assessment of environment impacts of egg production chain using life cycle assessment. J. Environ. Manage. 183, 980-987.

González-García, S., Gómez-Fernández, Z., Dias, A.C., Feijoo, G., Moreira, M.T., Arroja, L., 2014. Life Cycle Assessment of broiler chicken production: a Portuguese case study. J. Clean. Prod. 74, 125-134.

Heinonen, J., Säynäjoki, A., Junnonen, J.M., Pöyry, A., Junnila, S., 2016. Preuse phase LCA of a multi-story residential building: Can greenhouse gas emissions be used as a more general environmental performance indicator? Build. Environ. 95, 116125.

Hospido, A., Moreira, M.T., Feijoo, G., 2003. Simplified life cycle assessment of galician milk production. Int. Dairy J. 13, 783-796.

Iglesias, L., Laca, A., Herrero, M., Díaz, M., 2012. A life cycle assessment comparison between centralized and decentralized biodiesel production from raw sunflower oil and waste cooking oils. J. Clean. Prod. 37, 162-171.

Kalhor, T., Rajabipour, A., Akram, A., Sharifi, M., 2016. Environmental impact assessment of chicken meat production using life cycle assessment. IPA 3, 262-271.

Khatri, P., Jain, S., 2017.Environmental life cycle assessment of edible oils: A review of current knowledge and future research challenges. J. Clean. Prod. 152, 63-76. Koivunen, E., Tuunainen, P., Valkonen, E., Rossow, L., Valaja, J., 2014. Use of faba beans (Vicia faba L.) in diets of laying hens. AFSci 23, 165-172. 

leafless peas (Pisum sativum L) in laying hen diets. AFSci 24, 84-91. production systems; why do they differ and how to close the gap? Results of discussions with groups of farmers in The Netherlands, Switzerland and France, benchmarking and model calculations. Europ. Poult. Sci. 78, 1-10. Predicting the environmental impacts of chicken systems in the United Kingdom through a life cycle assessment: egg production systems. Poult Sci. 91, 26-40. 2017. http://www.mapama.gob.es/es/ (accessed 17 July 2017). Mattsson, B., Cederberg, C., Blix, L., 2000. Agricultural land use in life cycle assessment (LCA): case studies of three vegetable oil crops. J. Clean. Prod. 8, 283-292. MINETAD (Ministry of Energy, Tourism and Digital Agenda (Spain)), 2017. 405-417.

Noya I., González-García, S., Berzosa, J., Baucells, F., Feijoo, G., Moreira, M.T., 2017. Environmental and water sustainability of milk production in Northeast Spain. Sci. Total Environ. (in press).

Nijdam, D., Rood, T., Westhoek, H., 2012. The price of protein: Review of land use and carbon footprints from life cycle assessments of animal food products and their substitutes. Food Policy 37, 760-770. 
livestock and tree crops to improve sustainability in agriculture: a case study using the

544 Life Cycle Assessment (LCA) approach. J. Clean. Prod. 131, 351-363. Prod. 54, 108-114.

Pelletier, N., 2017. Life cycle assessment of Canadian egg products, with differentiation by hen housing system type. J. Clean. Prod. 152, 167-180. 2017. Life cycle assessment of cheese production process in a small-sized dairy industry in Brazil. E.S.P.R. 24, 3470-3482.

Saswattecha, K., Kroeze, C., Jawjit, W., Hein, L., 2015. Assessing the environmental impact of palm oil produced in Thailand. J. Clean. Prod. 100, 150-169. Poultry Meat Chain - LCA Approach. Procedia Food Sci. 5, 258-261. fruit growers association impacts assessment by using combined LCA and s-LCA methodologies. Sci. Total Environ. 568, 253-262. in life cycle assessment implementation in fisheries. Improving and broadening 562 environmental assessment for seafood production systems. Trends Food Sci. Technol. $56328,116-131$. 

towards sustainability in pork meat production. Meat Sci. 109, 13-17.

570 environmental impacts from Australian chicken meat production. J. Clean. Prod. 140, $571 \quad 675-684$.

572 Xu, X., Lan, Y., 2016. A comparative study on carbon footprints between plant573 and animal-based foods in China. J. Clean. Prod. 112, 2581-2592. 


\section{FIGURE CAPTIONS}

Figure 1. System boundaries referred to the functional unit expressed per functional unit (FU = 13344000 eggs).

Figure 2. Characterization results obtained using ReCiPe Midpoint.

Figure 3. Normalization results obtained using ReCiPe Endpoint.

Figure 4. Normalization results obtained using Greenhouse Gas Protocol.

Figure 5. Normalization results obtained using ReCiPe Midpoint. Comparison of the most significant categories for three different scenarios: Scenario 1 (real data), Scenario 2 (substituting soybean by pea in hen fodder) and Scenario 3 (substituting palm oil by cottonseed oil in hen fodder).

Figure 6. Normalization results obtained using Greenhouse Gas Protocol. Comparison of the carbon footprint values considering fossil and biogenic carbon for three different scenarios: Scenario 1 (real data), Scenario 2 (substituting soybean by pea in hen fodder) and Scenario 3 (substituting palm oil by cottonseed oil in hen fodder). 


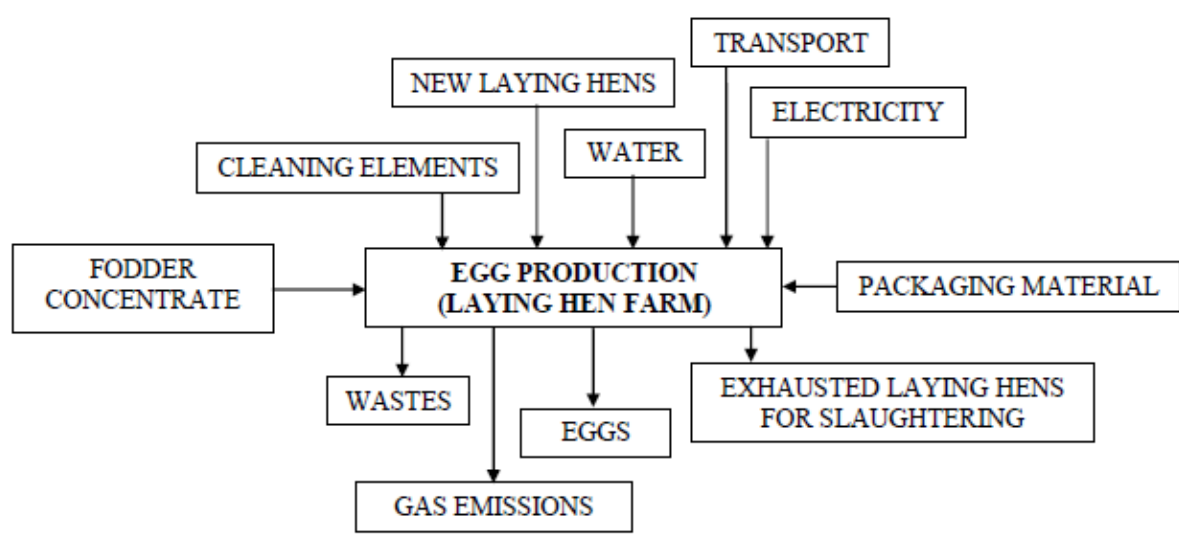




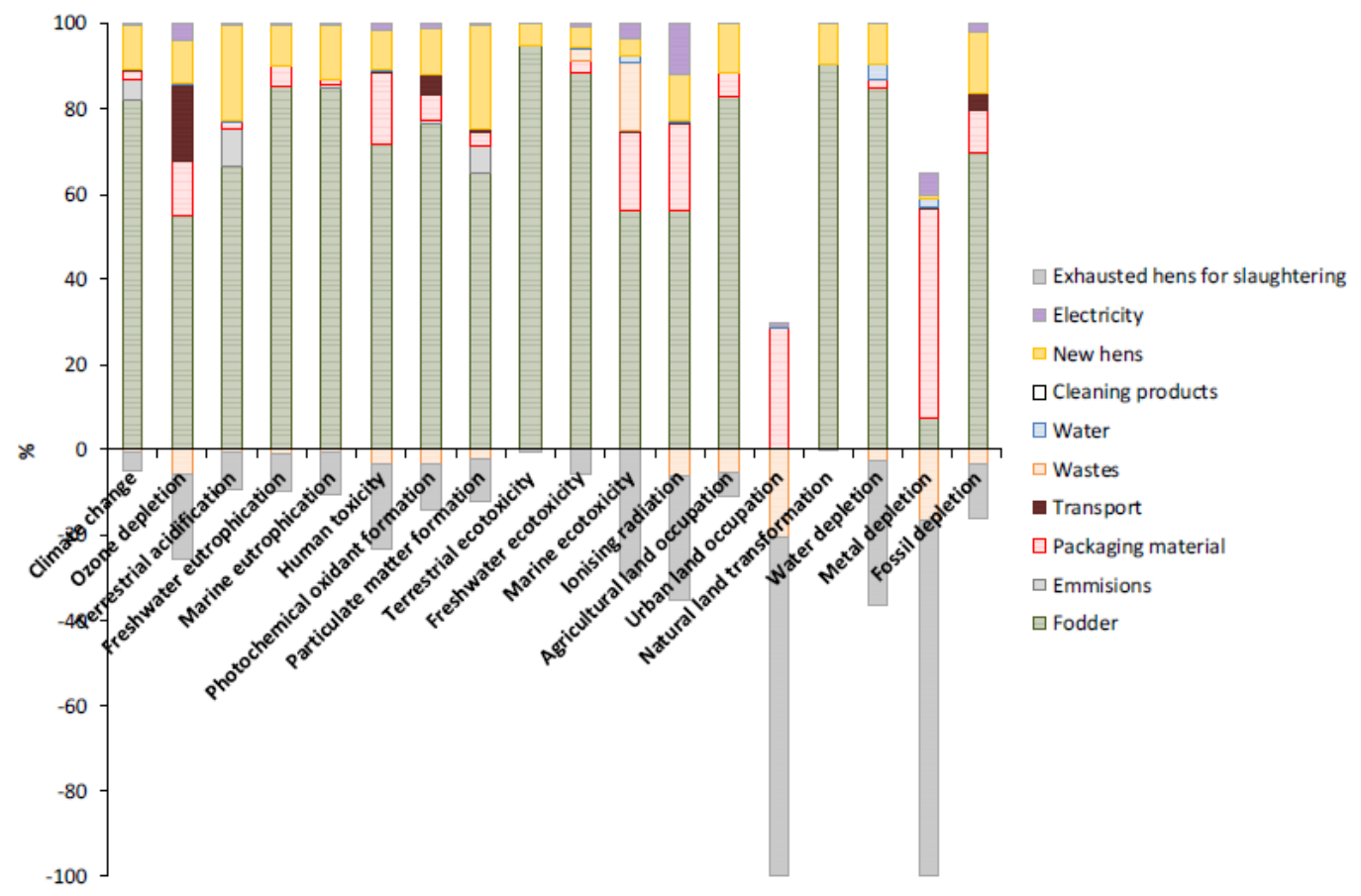




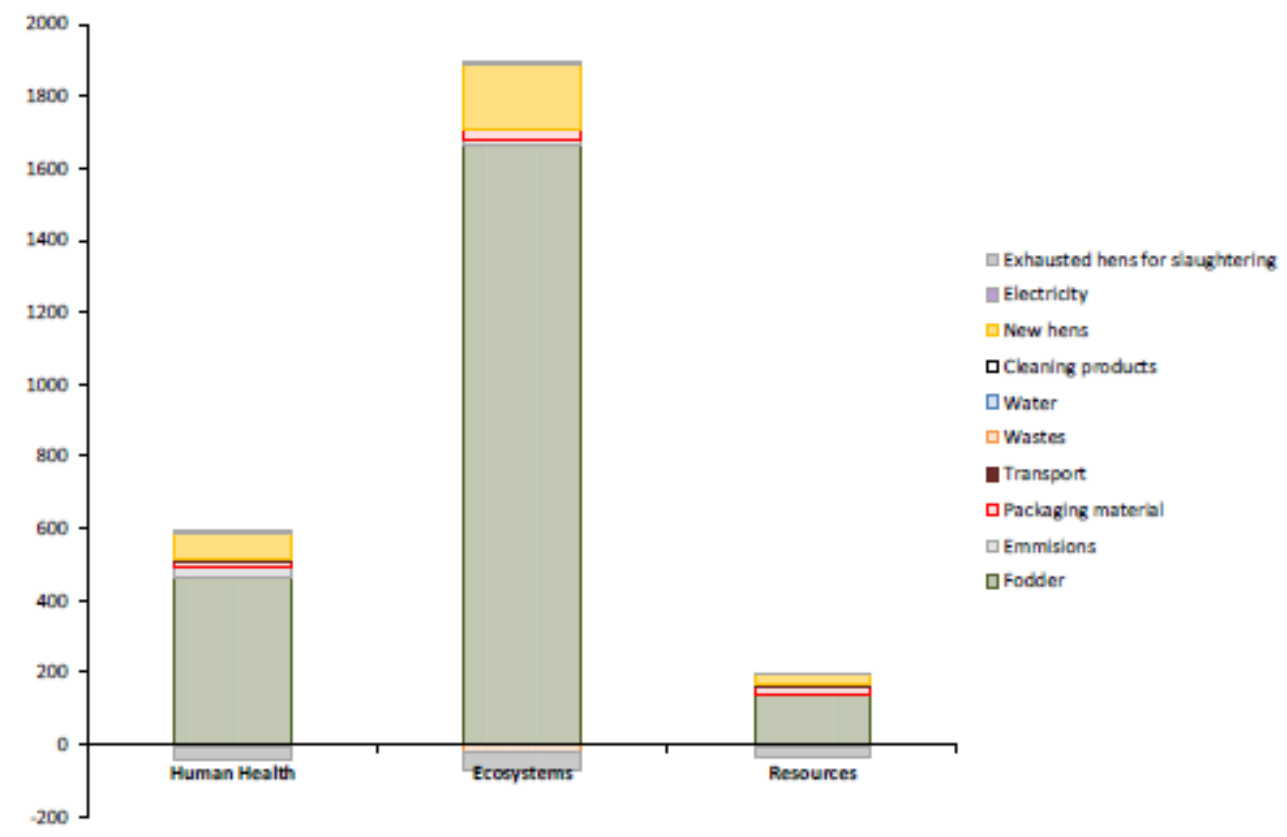




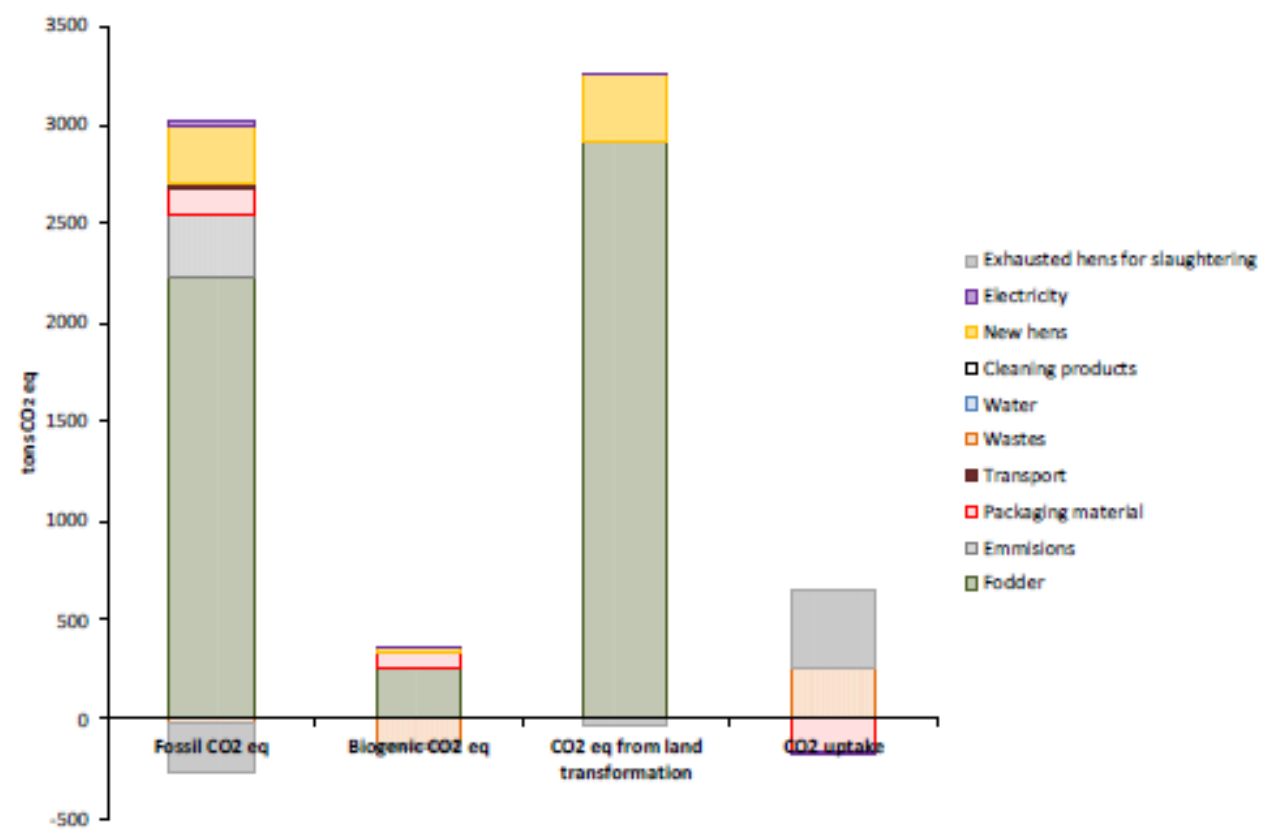



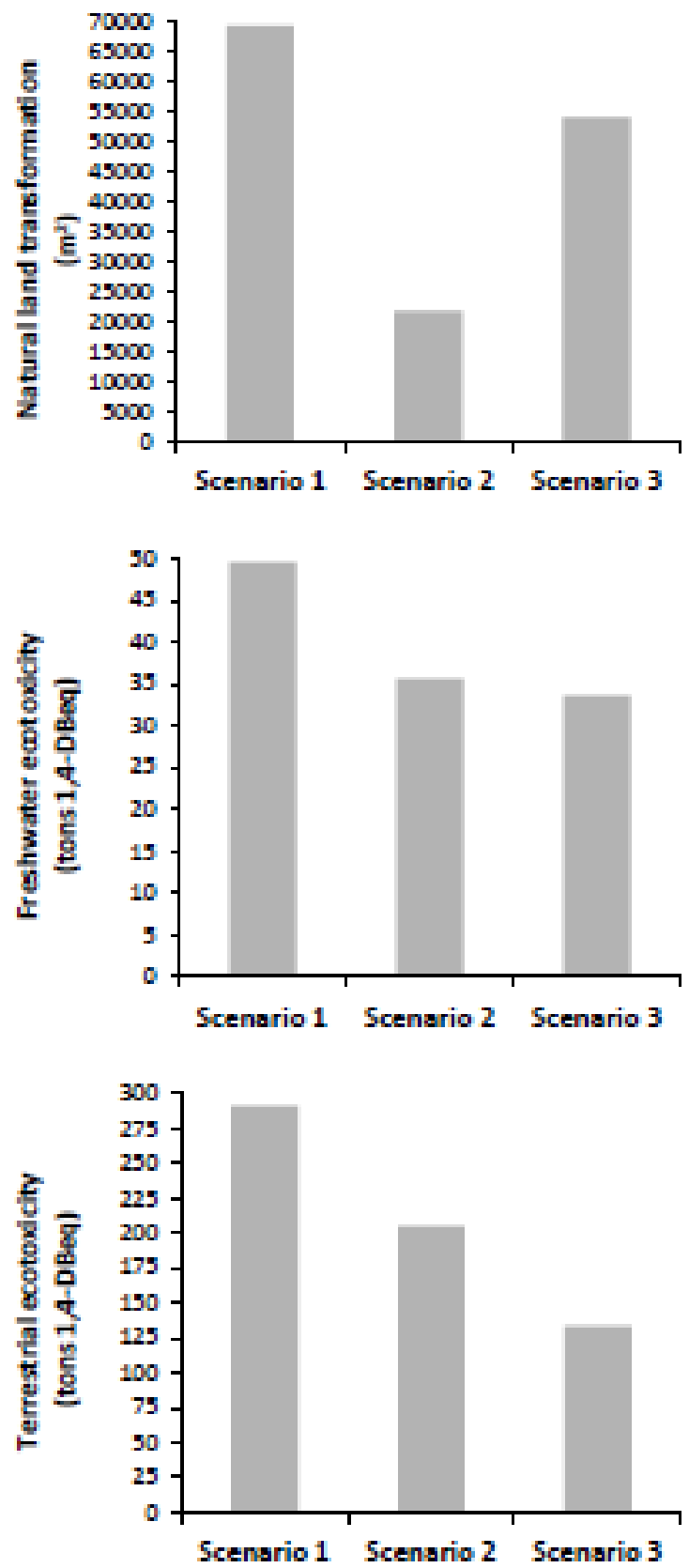


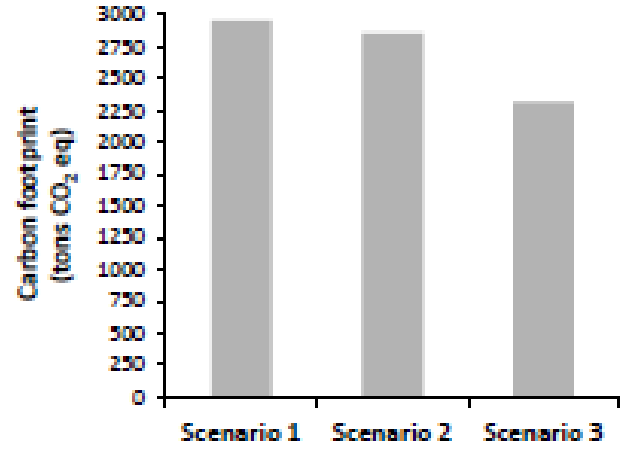


Table 1. Nutritional composition of the commercial fodder employed in the facility under study.

\begin{tabular}{lc}
\hline \multicolumn{1}{c}{ Component } & $0 \mathrm{c}(\mathbf{w} / \mathbf{w})$ \\
\hline Protein & 17.3 \\
Lipids & 4.0 \\
Fibre & 4.5 \\
Ash & 14.5 \\
Lysine & 0.85 \\
Methionine & 0.40 \\
Calchim & 4.1 \\
Sodium & 0.16 \\
Phosphorus & 0.51 \\
\hline
\end{tabular}


Table 2. Inventory data of the farm, expressed per functional unit (FU $1,334,4000 \mathrm{eggs}$.

\begin{tabular}{lc}
\hline \multicolumn{2}{c}{ Inputs } \\
\hline 1. New laying hens (units) & 55000 \\
2. Water $\left(m^{2}\right)$ & 3471 \\
3. Electricity (kWh) & 49369 \\
4. Cleaning products (bleach) (t) & 0.017 \\
5. Fodder (t) & \\
a. Maize $(50 \%)$ & 1200 \\
b. Soybean $(31 \%)$ & 744 \\
c. Palm oil $(11 \%)$ & 264 \\
d. Sodium bicarbanate $(8 \%)$ & 192
\end{tabular}

6. Packaging material (c)
a. Recycled cardboard
5670
b. Solid cardboard

7. Transport
a. By truck (thm)
54348642
b. Diesel $(\mathrm{t})$

3. Wastes
a. Wastewater (to treat) (m3)
b. Cardboard (to recycle) (t)
c. Manure (to be used as fertilizer) (t)
d. Municipal wastes (to landfill) (t)
e. Dead hens (hazardous waste for incineration) (c)

4. Emissions to air (t)
a. $\mathrm{CH}_{1}$
b. $\mathrm{N}_{2} \mathrm{O} \mathrm{N}$
0.42
c. $\mathrm{NH}_{3} \mathrm{~N}$
1.88 